\title{
Staphylococcus Pasteuri (BCVME2) Resident In Buffalo Cervical Vaginal Mucus (CVM) - A Potential Source of Estrus-Specific Sex Pheromone(s)
}

Mahalingam Srinivasan

Bharathidasan University

R. L. Rengarajan

Bharathidasan University

D. Dhanasekaran

Bharathidasan University

M. A. Akbarsha

National College Autonomous

Govindaraju Archunan ( $\nabla$ garchu56@yahoo.co.in )

Bharathidasan University

Research Article

Keywords: Bacteria, oestrous cycle, vaginal mucus, HS-GC-MS, volatile compounds

Posted Date: June 11th, 2021

DOl: https://doi.org/10.21203/rs.3.rs-500721/v1

License: (9) This work is licensed under a Creative Commons Attribution 4.0 International License.

Read Full License 


\section{Abstract}

There are microbes resident in the reproductive tract, some of which could be pathogenic while a few others would, perhaps, play important roles in protecting the reproductive tract from infections. Volatile compounds are known to play role as sex pheromones that attract the males for coitus during estrus or heat. It is likely that these compounds themselves are secondary metabolites of the bacterial flora resident in the vagina. In order to substantiate this hypothesis, bacteria were isolated from cervico-vaginal mucus (CVM) of buffalo during various phases of the oestrous cycle and identified, based on morphological, biochemical and molecular characteristics, as Bacillus during preestrus as well as diestrus, and Staphylococcus during all phases of the oestrous cycle. But, the populations of Staphylococcus differed between different phases of the oestrous cycle, the predominant forms being $S$. warneri (BCVMPE1_1) during preestrus, S. pastueri (BCVME2) during oestrus and S. epidermis (BCVMDE3) during diestrus. Mice, when used as sensors, efficiently differentiated the oestrus-specific $S$. pastueri (BCVME2) from the others. HS-GC-MS analysis showed that $S$. pastueri (BCVME2) produces key volatile compounds viz., acetic, propanoic, isobutyric, butyric, isovaleric and valeric acids. In addition, it is evidenced that $S$. pasteuri (BCVME2) volatiles influence the sexual behaviours such as flehmen and mounting of the bull. Thus, the paper reports that $S$. pasteuri (BCVME2) is the potential source of vaginal pheromone(s) during oestrus in buffalo.

\section{Introduction}

The cervico-vaginal mucus (CVM) microbial community is associated with reproductive health and fertility in mammals. For example, the cervical secretions are known to play crucial roles in the reproductive success of cows (Adnane et al. 2018). CVM of the healthy cow contains aerobic as well as anaerobic microbiota, especially those belonging to Enterobacteriaceae family, and also Staphylococcus sp., Streptococcus sp., Enterococcus sp. and Lactobacillus sp. (Otero et al. 1999; Wang et al. 2013). The CVM microbiota are influenced by hormonal, immunological and nutritional factors, and even the antibiotics and hormones that are used as drugs for treatment of the host (Otero et al. 2006). The dynamics of microbiota in the uterus and vagina have been well studied in the cows under various pathophysiological conditions (Ault et al. 2019; Bicalho et al. 2017a; Bicalho et al. 2017b; Bicalho et al. 2017c; Galvao et al. 2019). In buffalo, association of CVM microbiota with haematological parameters, such as counts of the white blood cells (WBC) lymphocytes, monocytes, granulocytes, etc., during the different phases of oestrous cycle has been reported (Joshi et al. 2020). The role of CVM bacteria in reproduction and pheromone releases in bovine has been reviewed in adequate detail (Srinivasan et al. 2021). However, elaborate investigation on estrus-specific bacteria in buffalo pheromone has not yet been taken up.

Research so far has revealed that the culture-independent method using next-generation sequencing (NGS) is appropriate to find the diversity of CVM microbiome with particular attention to the buffalo oestrous cycle (Srinivasan et al. 2019). Proteobacteria, Actinobacteria, Firmicutes, Bacteroidetes and Tenericutes are the most common CVM of buffalo. Among these five families, Firmicutes has been found 
to be highly abundant during oestrus compared to the other phases (Srinivasan et al. 2019). The volatile chemical compounds of CVM can vary among the phases of oestrous cycle, and it is well known that bulls are able to differentiate oestrus and non-oestrus cows based on pheromone(s) present in the vaginal secretion (Karthikeyan and Archunan 2013; Rajanarayanan and Archunan 2004; Sankar and Archunan 2004).

It has been documented that male dogs and mice differentiate oestrus and non-oestrus cows by sniffing the odour of vaginal fluid, urine, saliva, faeces and milk of the latter (Fischer-Tenhagen et al. 2013; Rameshkumar et al. 2008; Sankar and Archunan 2005). It has been established that bovine bulls exhibit flehmen and mounting behaviours after perceiving unique volatiles from females during oestrus (Karthikeyan et al. 2013; Rajanarayanan and Archunan 2004; Sankar and Archunan 2004). The flehmen is demonstration of the most distinct and important aspect of the premating behaviour. The flehmen behaviour of bulls has been used to identify and quantify pheromone production in buffaloes and cows (Karthikeyan et al. 2013; Rajanarayanan and Archunan 2004; Sankar and Archunan 2004).

Volatile compounds such as acetic acid and propanoic acid have been identified in cow vaginal mucus (Sankar and Archunan 2011) and oleic acid from buffalo vaginal secretion (Karthikeyan and Archunan 2013) during oestrus, which act as female sex pheromones. Interestingly, acetic acid has been found in buffalo urine, with a substantial increase in concentration during estrus relative to other phases of the oestrous cycle (Muniasamy 2016). The bacterial populations present in the CVM are reported to potentially affect the sexual attraction of ewes (Ungerfeld and Silva 2005). The report suggests that fatty acids may act as pheromones as well as estrus indicators in buffaloes and that these microbes might be responsible for the specific odour released at oestrus.

On the basis of substantial evidences, buffalo CVM has been shown to produce estrus-specific volatiles that affect the reproductive behaviour of male buffalo during mating. However, the source of the buffalo CVM pheromone compounds is not well established. Evidence for the impact of CVM bacteria and their role in production of volatiles in the context of male attraction towards female buffalo is inadequate. The present study was therefore intended to i) demonstrate the bacterial community in buffalo CVM through a culture-based method during different phases of the oestrous cycle, and (ii) screen the oestrus-specific bacteria using mice as model sensor system, iii) find if bacterial secretory substance contains volatiles, and iv) evaluate bull behaviour in response to estrus-specific bacterial secretory substance of CVM in order to confirm that the very bacterial volatiles are the pheromones that elicit specific premating behaviours in the males.

\section{Materials And Methods}

\section{Animal and sample collection}

The healthy female buffaloes $(n=12)$ and phases of oestrous cycle were monitored as per the protocol of Rajanarayanan and Archunan (2004). CVM collection was carried out based on the procedure and 
protocol of Laguardia-Nascimento et al. (2015).

\section{Isolation and characterization of bacteria}

For the isolation of bacteria, the CVM was collected from buffaloes representing the three phases of the oestrous cycle. CVM, $0.5 \mathrm{~mL}$, was homogenized in $4.5 \mathrm{~mL}$ of sterile distilled water. An aliquot of $0.1 \mathrm{~mL}$ of the homogenate was serially diluted and plated in Nutrient-MacConkey-De Man, Rogosa and Sharpe-and Mannitol salt- agar by standard plate count method (Cassoli et al. 2016). Plates were incubated at $37^{\circ} \mathrm{C}$ for 24-48 hr. Following the incubation, the bacterial colonies were counted and expressed by log values (Log CFU/mL i.e. Log10 (CFU / (dilution factor $x$ aliquot). Morphologically distinct colonies alone were picked and further processed. Primary characterization was carried out based on colony morphology which included colour, size and shape. Further, the isolates were subjected to Gram staining and biochemical tests for catalase, oxidase, sugar fermentation and haemolysis.

\section{Extraction of genomic DNA and PCR amplification of $16 S$ rRNA gene}

Genomic DNA of bacterial isolates was extracted based on the method of Vingataramin and Frost (2015). The quality of gDNA was evaluated on $1.0 \%$ agarose gel. Fragment of 16S rRNA gene was amplified by PCR with the primers 27F AGAGTTTGATCMTGGCTCAG and 1492R CGGTTACCTTGTTACGACTT. PCR reactions were executed in a total volume of $30 \mu \mathrm{L}$ containing $15 \mu \mathrm{L} 2$ X PCR premix, $2 \mu \mathrm{L}$ template DNA, $0.5 \mu \mathrm{L}$ each of the primer and $12 \mu \mathrm{L}$ sterile distilled water. The cycling parameters used were as follows: initial denaturation at $94^{\circ} \mathrm{C}$ for $3 \mathrm{~min}$, followed by 35 cycles of denaturation at $94^{\circ} \mathrm{C}$ for $30 \mathrm{sec}$, annealing at $50^{\circ} \mathrm{C}$ for $30 \mathrm{sec}$ and extension at $72^{\circ} \mathrm{C}$ for $90 \mathrm{sec}$, and then a final elongation at $72^{\circ} \mathrm{C}$ for $7 \mathrm{~min}$ (Coombs and Franco, 2003). Eurofins Genomics India Pvt. Ltd (Bangalore, India) conducted the 16S rRNA gene sequencing.

\section{Sequencing and phylogenetic analysis of 16S rRNA gene}

The amplicons were purified using pre-sequencing kit and sequenced on $A B I 3730 x I$ automated sequencer (Perkin Elmer Applied Biosystems, Foster City, CA, USA) and ABI Prism BigDye Terminator Cycle Sequencing Ready Reaction Kit when AmpliTaq ${ }^{\circledR}$ DNA polymerase was used as per protocols recommended by the manufacturer.

The dataset of 16S rRNA gene sequences was prepared for BLAST search. All individual representative sequences were performed at NCBI (Altschul et al. 1990). Sequences were obtained from BLAST searches based on E-value where identity scores differed depending on the size of the gene family. Nucleotide compositional parameters were predicted from BioEdit 7.0.4 (Hall 2011). Besides the BLAST results, 16S rRNA gene sequences of the most closely related taxa were retrieved from the GenBank database and 
aligned using the ClustalW tool implemented in MEGA X (Kumar et al. 2018). MEGA X was used to reconstruct the phylogenetic tree adopting neighbour-joining $(\mathrm{NJ})$ method using bootstrap values based on 1000 replications (Kim et al. 2019). 16S rRNA gene sequences were deposited in NCBI database using Banklt (http://www.ncbi.nlm.nih.gov).

\section{Isolation of volatiles from bacterial culture}

The selected bacterial colonies from CVM collected during various phases of oestrous cycle (i.e. preestrus, estrus and diestrus) were inoculated in $250 \mathrm{~mL}$ of LB (Luria Bertani) broth and incubated in rotary shaker at $150 \mathrm{rpm}$ for $48 \mathrm{hr}$. Further, the culture was centrifuged at $5000 \mathrm{x} \mathrm{g}$ for $10 \mathrm{~min}$ (Tredwell et al. 2011). The supernatant was subjected to further studies.

\section{Discrimination of bacterial volatiles using mice}

Screening of bacteria odour was performed using mice as the odour detector (Sankar and Archunan 2005). Twenty four male mice (12 week old) were used for the odour preference and the study was performed by Y-maze apparatus made of tin sheets and glass plates (Sankar and Archunan 2005). The behaviour study was conducted according to the standard protocol (Achiraman and Archunan, 2006). The bacterial supernatants $(100 \mu \mathrm{L})$ were presented in $2 \mathrm{~mL}$ vials having minute pores and mice were introduced into the central chamber to begin in a common place, and the duration and number of visits were observed for $15 \mathrm{~min}$. Three mice were used as test animals for each sample. Use of mice in this experiment was approved by the Institutional Ethics Committee (IAEC) of Bharathidasan University (BDU/IAEC/2017/NE/13Dt.21.03.2017). Ultimately, the potential odour-producing bacterial isolates were selected and taken to further HS-GC-MS analysis.

\section{Identification of bacterial volatiles adopting headspace gas chromatography-mass spectrometry (HS-GC/MS)}

The supernatant $(1 \mathrm{~mL})$ collected from $S$. pasteuri culture was subjected to HS analysis. HS-GC/MS analysis was performed on an Agilent mass spectrometer (Agilent Technologies, DE, USA) coupled with GC system (5977 MSD, 7679A Headspace Sampler, Agilent Technologies). Bacterial volatiles were separated by capillary GC column DB-VRX (20 m x $180 \mu \mathrm{m} \times 1 \mu \mathrm{m})$. Helium was used as the carrier gas at a flow rate of $1 \mathrm{~mL} / \mathrm{min}$. The chromatographic conditions for the analysis was as follows: a) initial temperature $40^{\circ} \mathrm{C}$, for $\left.3 \mathrm{~min}, \mathrm{~b}\right) 150^{\circ} \mathrm{C}$ for $1 \mathrm{~min}$ at a rate of $7^{\circ} \mathrm{C} / \mathrm{min}$, and c) $240^{\circ} \mathrm{C}$ at a rate of $60^{\circ} \mathrm{C}$. Samples $(1 \mu \mathrm{L})$ were injected in split mode $(30 \mathrm{sec})$ and the split ratio was 10:1. The separated compounds were ionized by electron energy at $70 \mathrm{eV}$ in positive ion mode. Peak identification was done based on mass spectral interpretation and comparisons using NIST National Institute of Standard and Technology (NIST) library (Boots et al. 2014). 


\section{Bull behavioural observation towards CVM bacterial volatile samples}

Non-estrus female buffaloes $(n=6)$ and bulls $(n=6)$ were selected for the behaviour studies. The supernatant of bacterial culture, estrus CVM, non-estrus CVM and LB broth were subjected to bull behaviour analysis. Each sample $(5 \mathrm{~mL})$ was individually soaked in cotton and rubbed on the vulvar region of non-estrus buffalo (i.e. dummy cow). The bulls were allowed to sniff the test animals, and behaviours were observed for 30 min (Karthikeyan and Archunan 2013). The flehmen and mounting behaviours exhibited by the bull in response to the test samples were recorded.

\section{Statistical analysis}

Analysis of variance (ANOVA) was carried out for behaviour data analysis by using SPSS (V.2.3) package, and images were plotted in GraphPad Prism (V.8.0.2).

\section{Results}

\section{Isolation of bacteria from buffalo CVM}

The bacteria isolated from CVM during preestrus, estrus and diestrus were present as $38 \mathrm{CFU} / \mathrm{mL}, 51$ $\mathrm{CFU} / \mathrm{mL}$ and $36 \mathrm{CFU} / \mathrm{mL}$, respectively as determined adopting serial dilution method. Thus, cumulatively as many as 125 bacterial colonies were observed covering all three phases. Amongst them, 6 isolates were chosen, based on morphological characters such as smoothness and colour (white or creamy yellow), for higher level analyses. Biochemical characterization such as Gram staining, sugar fermentation tests (glucose, fructose, maltose and sucrose) and haemolytic assay showed (Table S1). The bacteria found in oestrus CVM are Gram positive, non-haemolytic, and fermentable sugars, including glucose, fructose, maltose, and sucrose, with acid production.

Molecular characterization of bacterial isolates showed that expression of Staphylococcus community differed between the three phases of the oestrous cycle, as follows: Staphylococcus warneri (BCVMPE1_1) during preestrus, S. pasteuri (BCVME2) during estrus and S. epidermidis (BCVMDE3) during diestrus. With regard to Bacillus resident in CVM, B. subtilis (BCVMPE1) and B. toyonensis (BCVMPE2) were limited to preestrus, whereas $B$. proteolyticus (BCVMDE5) showed up only during diestrus. The sequences have been deposited at NCBI under the accession number: MT789231.1 (BCVMPE1_1), MT705012.1 (BCVMPE2), MT598012.1 (BCVMPE1), MT598013.1 (BCVME2), MT598014.1 (BCVMDE3), and MT705014.1 (BCVMDE5).

\section{Construction of the phylogenetic tree}


Pairwise 16S rRNA gene sequence similarities were determined using BLASTn analysis. Based on the identity ( $98 \%$ and above from the query coverage) the species was selected. The variations in nucleotide composition were identified for CVM bacterial isolates (in percentage as well as numbers). $\mathrm{G}+\mathrm{C}$ base pair was found to be high, above $52 \%$ (Table S2). NCBI-BLAST was practiced to identify isolates having > $98 \%$ similar sequence at inter- and intra-specific levels. The result showed that the tree could be grouped into two major clusters. The first cluster consists of various species of Staphylococcus genus; the second cluster consists of Bacillus species as represented in phylogenetic tree analysis (Fig. 1A). The molecular taxonomic characterization showing the differential expression in respect to three phases of oestrous cycle is presented in Fig. 1B.

\section{Discrimination of the bacterial volatiles from CVM adopting mice behavioural assay}

There were significant differences among the bacterial volatiles across different phases of the oestrous cycle. The behavioural assessment of the mice revealed greater attraction towards estrus-specific bacteria than the non-estrus bacterial sample (Fig. 2). The estrus-specific bacterial volatiles was found to be most attractive as mice visited them frequently and spent more time than the non-estrus bacterial volatiles $(p<0.001)$. The behavioural study further expounded that the estrus $S$. pasteuri (BCVME2) most attracted the mice.

\section{Identification of volatiles produced by bacteria as revealed in headspace GC-MS}

The GC-MS analysis of cell free supernatant of estrus-specific bacteria isolated from CVM revealed the nature of volatiles (Fig. 3). Six volatiles viz., acetic acid, propanoic acid, isobutyric acid, butyric acid, isovaleric acid and valeric acid are produced by S. pasteuri (Table 1). Acetic acid appeared to be at a higher peak intensity among bacterial volatiles, followed by isovaleric acid, valeric acid, isobutyric acid, butyric acid, and propanoic acid.

Table 1: Volatile compounds of S. pasteuri (BCVME2) isolated from buffalo CVM. 


\section{Volatile compounds Molecular weight Chemical structure}

Acetic acid 60.05

Propanoic acid

74.07

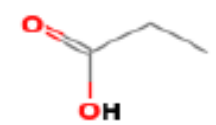

Isobutyric acid

88.10

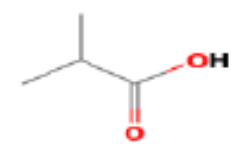

Butyric acid

88.10

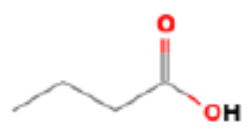

Isovaleric acid

102.13

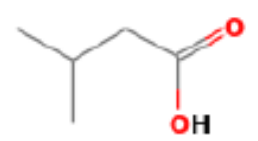

Valeric acid

102.13

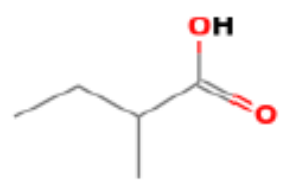

\section{Bull behaviour conditioned by the volatiles of $S$. pasteuri}

The bulls were attracted to the maximum towards intact estrus CVM followed by supernatant of $S$. pasteuri, LB broth, and non-estrus CVM. The frequency of flehmen response exhibited by bull was highest to the intact estrus CVM $(5.83 \pm 1.16)$ as well as $S$. pasteuri secretory substance $(4.66 \pm 1.21)$. By contrast, bull showed significantly lesser attraction to non-estrus CVM $(0.67 \pm 1.03)$ and no response at all to LB 
broth. Likewise, the mounting behaviour exhibited by bull was remarkably higher towards intact estrus CVM $(4.83 \pm 1.94)$ and $S$. pasteuri secretory substance $(4.5 \pm 1.64)$. However, bull showed less response towards non-estrus CVM $(0.5 \pm 1.22)$ and no response at all towards LB broth. However, the flehmen and mounting behaviours observed during exposure to estrus CVM sample and S. pasteuri secretory substance are almost similar in response. Details of flehmen and mounting behaviours of bull are given in Fig. 4.

\section{Discussion}

Our previous study showed differences in the CVM bacterial community with respect to various phases of the oestrous cycle (Srinivasan et al. 2019), in which the Firmicutes phylum was more abundant during the oestrus phase. Probably, expression of certain specific bacterial genes is higher during estrus phase than the other phases. The present investigation revealed expression of specific gene(s) in S. pasteuri during the estrus phase. The available information indicates that the CVM bacterial strains get influenced during estrus in buffalo. It has also been reported that the vaginal bacterial population is affected by the cyclical variation during the oestrous cycle (Otero et al. 1999; Otero et al. 2000).

In the present study, S. pasteuri were incidentally observed in buffalo CVM during estrus. Similar studies have been reported in various animals. Association of vaginal Simonsiella spp in reference to estrus phase has been documented in lions and leopards (Callealta et al. 2018). It is interesting to note that Streptococcus and Staphylococcus are the most dominant bacteria in healthy cows during the reproductive cycle (Amin et al. 1996). Staphylococcus (70\%) and Escherichia (15\%) were observed more frequently during natural and induced estrus of ewes (Orihuela et al. 2019) and all the isolates had a high sensitivity to ciprofloxacin antimicrobials that evaluated vaginitis regulation (Mohammed et al. 2017). The present finding supports the previous report of the presence of Staphylococcus pasteuri, which comes under the phylum Firmicutes, and is abundant during estrus (Srinivasan et al. 2019).

In addition, bacteria such as Bacillus spp., Staphylococcus spp., and Streptococcus spp., have been identified in vagina of ewe (Manes et al. 2010) as well as cows (Otero et al. 1999; Otero et al. 2000; Zambrano-Nava et al. 2011). These reports match with the present finding of bacterial community identified in CVM of buffalo. On the other hand, major bacterial genera in the vagina of Gyr and Nellore breed cows include Aeribacillus, Bacillus, Clostridium, Bacteroides and Ruminococcus (GiannattasioFerraz et al. 2019). The present analysis also depicted the presence of Bacillus spp. in buffalo exclusively during preestrus and diestrus phases. Notably, Lactobacilli were found to be very low in bovine vaginal microbiota which was confirmed by culture-dependent and culture-independent methods (Otero et al. 2000; Quereda et al. 2020; Srinivasan et al. 2019). The present finding reveals the absence of Lactobacillus sp. in buffalo CVM. Overall, the results obtained in the present study are consistent with previous reports.

The mice system was used to screen the volatile compound samples. Among 7 samples tested with mice, S. pasteuri secretory substance exhibited to be more attractive than the other cultures. The results are 
consistent with an earlier report that mice are capable of discriminating the estrus and non-estrus samples. A recent study provides supportive evidence that mice are highly sensitive to volatiles produced by the microbes (Peixoto et al. 2018). Truly, the mice study helped to pick out the bacteria potentially responsible for volatiles production.

GC-MS analysis indicated six volatiles, acetic acid, propanoic acid, isobutyric acid, butyric acid, isovaleric acid and valeric acid, as produced by $S$. pasteuri. It is known that short-chain fatty acids such as acetic-, propanoic- and butyric acid, are relatively abundant due to bacterial fermentation in colonic lumen which regulate entero-pathogenic colonization by host immunomodulation in human (Smith et al. 2013; Wrigley 2004). A recent study shows that acetic, valeric, caproic and myristoleic acids are at significantly higher levels in the milk of estrus cow (Zebari et al. 2019). The fatty acids, acetic and propanoic, have been identified in the faeces of cow, and varied in relation to the time of ovulation (Mozūraitis et al. 2017). The present investigation supports the previous reports of presence of acetic, propanoic and valeric acids as produced by CVM bacteria in estrus buffalo.

Since estrus-specific $S$. pasteuri produces volatiles, we focused on testing the role of $S$. pasteuri secretory substance in bull behaviours which confirmed the estrus-specificity and its use as a reliable estrus indicator. Interestingly, bull exhibited reproductive behaviours such as flehmen and mounting, which are important in assessing sexual desire of bull as response to $S$. pasteuri secretory substance. The present study also corroborates previous findings that the estrus-specific faeces pheromone has a significant effect on flehmen and mounting behaviour in buffalo (Karthikeyan et al. 2013). It has been reported that bulls exhibit this reproductive behavioural patterns in response to the presence of a mixture of volatiles in the CVM of estrus cow (Karthikeyan and Archunan 2013; Rajanarayanan and Archunan 2004; Sankar and Archunan 2004). Vaginal pheromones have been reported to be acetic acid, propanoic acid, and 1iodoundane, in cows (Sankar and Archunan 2004) and oleic acid as an estrus indicator in buffalo (Karthikeyan and Archunan 2013) to stimulate flehmen and mounting behaviour response in bulls. The present findings suggest that the volatile compounds of bacterial origin may act as attractants of the bull and induce the olfactory system to elicit flehmen and mounting behaviours in order to maintain the health and management during reproduction. Since $S$. pasteuri is capable of secreting the volatiles viz., acetic, propanoic, isobutyric, butyric, isovaleric, and valeric acids, they can be considered as major bacterial volatiles that induce the buffalo bull's sexual behaviour. For instance, acetic acid, 2-butanone and oleic acid have been shown to improve Zebu bull sexual behaviour and total sperm production (Mondal et al., 2019). Thus, this study reports the presence in the buffalo vaginal fluid of volatile compounds secreted by CVM bacteria which facilitate the expression of male reproductive behaviours, which in turn suggests that these volatiles are putative pheromone compounds produced during oestrus in buffalo.

Further studies are needed to find the mechanisms associated with the specific effects of $S$. pasteuri volatiles. Characterization of protein profile of $S$. pasteuri from buffalo CVM during estrus is required to understand the host-bacterial interaction and their role in chemo-signal communication that would enlighten the reproduction management in buffaloes. 


\section{Declarations}

\section{Acknowledgements}

GA acknowledges the award of BSR Faculty Fellowship by the UGC, New Delhi, [F. No: 18 -1/2011 (BSR) dt: 04.01.2017]. The facility availed from DST-FIST II \& DST-PURSE schemes of Government of India is also gratefully acknowledged.

\section{Funding}

Not applicable

\section{Conflicts of interest/Competing interests}

The authors declare no conflicts of interest.

\section{Availability of data and materials}

Not applicable

\section{Code availability}

Not applicable

\section{Authors' contributions}

MS: Conceptualization, Investigation, Writing original manuscript. RLR: Data interpretation. DD: Conceptualization, Contributed to isolation of bacteria and culture methods. MAA: review \& editing, GA: Conceptualization, Supervision, review \& editing.

\section{Ethics approval}

Not applicable

\section{Consent to participate}

Not applicable 


\section{Consent for publication}

All authors are agreed for the article communication and publication.

\section{References}

1. Adnane M, Meade KG, O'Farrelly C (2018) Cervico-vaginal mucus (CVM) - an accessible source of immunologically informative biomolecules. Vet Res Commun 42:255-263. doi:10.1007/s11259-0189734-0

2. Altschul SF, Gish W, Miller W, Myers EW, Lipman DJ (1990) Basic local alignment search tool. J Mol Biol 215:403-410. doi:10.1016/S0022-2836(05)80360-2

3. Amin J, Zaria L, Malgwi R (1996) Vaginal aerobic bacterial flora of apparently healthy cattle in various stages of the reproductive cycle in the Sahel region of Nigeria Bull. Anim Heal Prod Africa $44: 15-18$

4. Ault TB et al (2019) Uterine and vaginal bacterial community diversity prior to artificial insemination between pregnant and nonpregnant postpartum cows. J Anim Sci 97:4298-4304. doi:10.1093/jas/skz210

5. Bicalho MLS, Lima S, Higgins CH, Machado VS, Lima FS, Bicalho RC (2017a) Genetic and functional analysis of the bovine uterine microbiota. Part II: Purulent vaginal discharge versus healthy cows. J Dairy Sci 100:3863-3874. doi:10.3168/jds.2016-12061

6. Bicalho MLS, Machado VS, Higgins CH, Lima FS, Bicalho RC (2017b) Genetic and functional analysis of the bovine uterine microbiota. Part I: Metritis versus healthy cows. J Dairy Sci 100:38503862. doi:10.3168/jds.2016-12058

7. Bicalho MLS, Santin T, Rodrigues MX, Marques CE, Lima SF, Bicalho RC (2017c) Dynamics of the microbiota found in the vaginas of dairy cows during the transition period: Associations with uterine diseases and reproductive outcome. J Dairy Sci 100:3043-3058. doi:10.3168/jds.2016-11623

8. Boots AW et al (2014) Identification of microorganisms based on headspace analysis of volatile organic compounds by gas chromatography-mass spectrometry. J Breath Res 8:027106. doi:10.1088/1752-7155/8/2/027106

9. Callealta I, Ganswindt A, Goncalves S, Mathew A, Lueders I (2018) Detection of Simonsiella spp. in the Vagina of Lions and Leopard in Oestrus. Reprod Domest Anim 53:1605-1608. doi:10.1111/rda.13298

10. Cassoli LD, Lima WJ, Esguerra JC, Da Silva J, Machado PF, Mourao GB (2016) Do different standard plate counting (IDF/ISSO or AOAC) methods interfere in the conversion of individual bacteria counts to colony forming units in raw milk? J Appl Microbiol 121:1052-1058. doi:10.1111/jam.13227

11. Galvao KN, Bicalho RC, Jeon SJ (2019) Symposium review: The uterine microbiome associated with the development of uterine disease in dairy cows. J Dairy Sci 102:11786-11797. doi:10.3168/jds.2019-17106 
12. Giannattasio-Ferraz $S$ et al (2019) A common vaginal microbiota composition among breeds of Bos taurus indicus (Gyr and Nellore). Braz J Microbiol 50:1115-1124. doi:10.1007/s42770-019-00120-3

13. Hall T (2011) BioEdit: an important software for molecular biology. GERF Bull Biosci 2:60-61

14. Joshi CG, Bagatharia SB, Joshi M, Patil DB, Suthar VS, Mahesh P (2020) Vaginal microbiota during estrous cycle and its plausible association with certain hematological parameters in bubalus bubalis. Indian J Anim Sci Biotechnol 15:54-58. doi:10.21887/ijvsbt.15.4.11

15. Karthikeyan K, Archunan G (2013) Gas chromatographic mass spectrometric analysis of estrus specific volatile compounds in buffalo vaginal mucus after initial sexual foreplay. J Buffalo Sci 2:17. doi:10.6000/1927-520x.2013.02.01.1

16. Karthikeyan K, Muniasamy S, SankarGanesh D, Achiraman S, Ramesh Saravanakumar V, Archunan G (2013) Faecal chemical cues in water buffalo that facilitate estrus detection. Anim Reprod Sci 138:163-167. doi:10.1016/j.anireprosci.2013.02.017

17. Kim J, Disanto F, Kopelman NM, Rosenberg NA (2019) Mathematical and simulation-based analysis of the behavior of admixed taxa in the neighbor-joining algorithm. Bull Math Biol 81:452-493. doi:10.1007/s11538-018-0444-0

18. Kumar S, Stecher G, Li M, Knyaz C, Tamura K (2018) MEGA X: Molecular evolutionary genetics analysis across computing platforms. Mol Biol Evol 35:1547-1549. doi:10.1093/molbev/msy096

19. Laguardia-Nascimento $\mathrm{M}$ et al (2015) Vaginal microbiome characterization of nellore cattle using metagenomic analysis. Plos One 10:e0143294. doi:10.1371/journal.pone.0143294

20. Mohammed KM, Nabih AM, Darwish GM (2017) Efficacy of anti-microbial agents on vaginal microorganisms and reproductive performance of synchronized estrus ewes. Asian Pacific J Reprod 6:121-127. doi:10.12980/apjr.6.20170305

21. Mozūraitis R, Kutra J, Borg-Karlson A-K, Būda VJJods (2017) Dynamics of putative sex pheromone components during heat periods in estrus-induced cows. J Dairy Sci 100:7686-7695. doi:10.3168/jds.2016-12376

22. Muniasamy S (2016) Detection of estrus from urinary chemo-signals in murrah buffalo (Bubalus bubalis). Bharathidasan University

23. Orihuela A, Fierros-Garcia A, Hallal-Calleros C, Robles-Castro SR, Ungerfeld R (2019) Vaginal biota number is smaller in tailed than docked hair ewes (Ovis aries), but is not affected by copulation. Trop Anim Health Prod 51:993-995. doi:10.1007/s11250-018-1753-x

24. Otero C, de Ruiz CS, Ibanez R, Wilde OR, Holgado AAPD, Nader-Macias ME (1999) Lactobacilli and enterococci isolated from the bovine vagina during the estrous cycle. Anaerobe 5:305-307. doi:DOI 10.1006/anae.1999.0245

25. Otero C, Saavedra L, Silva de Ruiz C, Wilde O, Holgado AR, Nader-Macias ME (2000) Vaginal bacterial microflora modifications during the growth of healthy cows. Lett Appl Microbiol 31:251-254. doi:10.1046/j.1365-2672.2000.00809.x

26. Otero MC, Morelli L, Nader-Macias ME (2006) Probiotic properties of vaginal lactic acid bacteria to prevent metritis in cattle. Lett Appl Microbiol 43:91-97. doi:10.1111/j.1472-765X.2006.01914.x 
27. Peixoto L, Salazar LTH, Laska M (2018) Olfactory sensitivity for mold-associated odorants in CD-1 mice and spider monkeys. J Comp Physiol A Neuroethol Sens Neural Behav Physiol 204:821-833. doi:10.1007/s00359-018-1285-x

28. Quereda JJ et al (2020) Vaginal microbiota changes during estrous cycle in dairy heifers. Front Vet Sci 7. doi:10.3389/fvets.2020.00371

29. Rajanarayanan S, Archunan G (2004) Occurrence of flehmen in male buffaloes (Bubalus bubalis) with special reference to estrus. Theriogenology 61:861-866.

doi:10.1016/j.theriogenology.2003.07.004

30. Sankar R, Archunan G (2004) Flehmen response in bull: role of vaginal mucus and other body fluids of bovine with special reference to estrus. Behav Processes 67:81-86.

doi:10.1016/j.beproc.2004.02.007

31. Sankar R, Archunan G (2005) Discrimination of bovine estrus-related odors by mice. J Ethol 23:147151. doi:10.1007/s10164-004-0140-4

32. Sankar R, Archunan G (2011) Gas chromatographic/mass spectrometric analysis of volatile metabolites in bovine vaginal fluid and assessment of their bioactivity. Int $\mathrm{J}$ Anal Chem 2011:256106. doi:10.1155/2011/256106

33. Smith PM et al (2013) The microbial metabolites, short-chain fatty acids, regulate colonic Treg cell homeostasis. Science 341:569-573. doi:10.1126/science.1241165

34. Srinivasan M, Adnane M, Archunan G (2021) Significance of cervico-vaginal microbes in bovine reproduction and pheromone production - A hypothetical review. Res Vet Sci 135:66-71. doi:https://doi.org/10.1016/j.rvsc.2021.01.003

35. Srinivasan M, Dhanasekaran D, Archunan G (2019) Vaginal microbiome analysis of buffalo (Bubalus bubalis) during estrous cycle using high-throughput amplicon sequence of 16S rRNA gene. Symbiosis 78:97-106. doi:10.1007/s13199-018-00595-y

36. Tredwell GD, Edwards-Jones B, Leak DJ, Bundy JG (2011) The development of metabolomic sampling procedures for Pichia pastoris, and baseline metabolome data. Plos One 6:e16286. doi:10.1371/journal.pone.0016286

37. Ungerfeld R, Silva $L$ (2005) The presence of normal vaginal flora is necessary for normal sexual attractiveness of estrous ewes. Appl Anim Behav Sci 93:245-250. doi:10.1016/j.applanim.2004.11.014

38. Vingataramin L, Frost EH (2015) A single protocol for extraction of gDNA from bacteria and yeast. Biotechniques 58:120-125. doi:10.2144/000114263

39. Wang Y, Ametaj BN, Ambrose DJ, Ganzle MG (2013) Characterisation of the bacterial microbiota of the vagina of dairy cows and isolation of pediocin-producing Pediococcus acidilactici. BMC Microbiol 13:19. doi:10.1186/1471-2180-13-19

40. Wrigley DM (2004) Inhibition of Clostridium perfringens sporulation by Bacteroides fragilis and shortchain fatty acids. Anaerobe 10:295-300. doi:10.1016/j.anaerobe.2004.05.006 
41. Zambrano-Nava S, Boscan-Ocando J, Nava J (2011) Normal bacterial flora from vaginas of Criollo Limonero cows. Trop Anim Health Prod 43:291-294. doi:10.1007/s11250-010-9701-4

42. Zebari HM, Rutter SM, Bleach ECL (2019) Fatty acid profile of milk for determining reproductive status in lactating Holstein Friesian cows. Anim Reprod Sci 202:26-34. doi:10.1016/j.anireprosci.2019.01.004

\section{Figures}
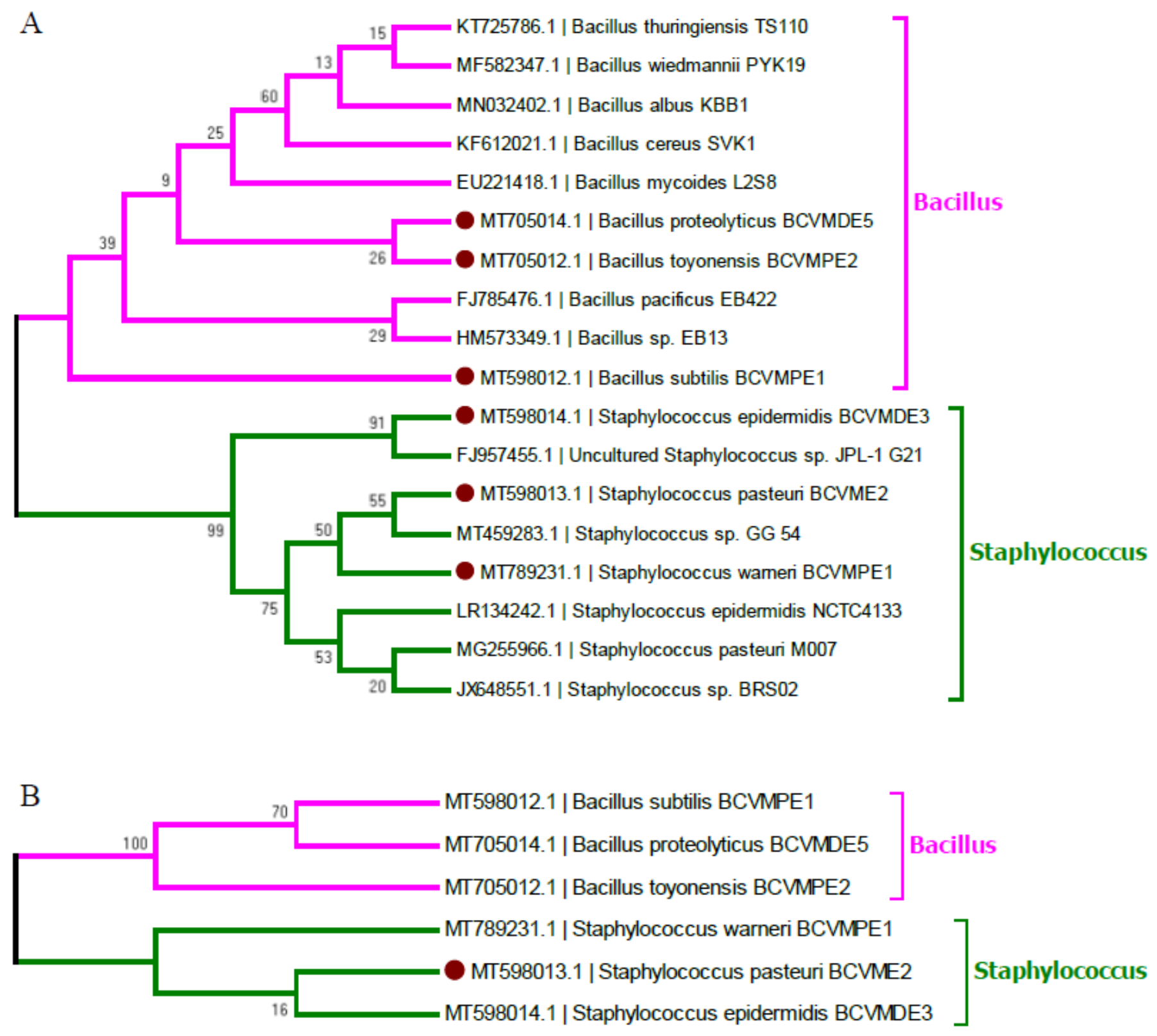

Figure 1

The phylogenetic tree. A. The inter- and intra-specific evolutionary relationship of the strains isolated from CVM. B. Highlight of the specific expression of bacterial isolates in CVM during the estrus phase. 


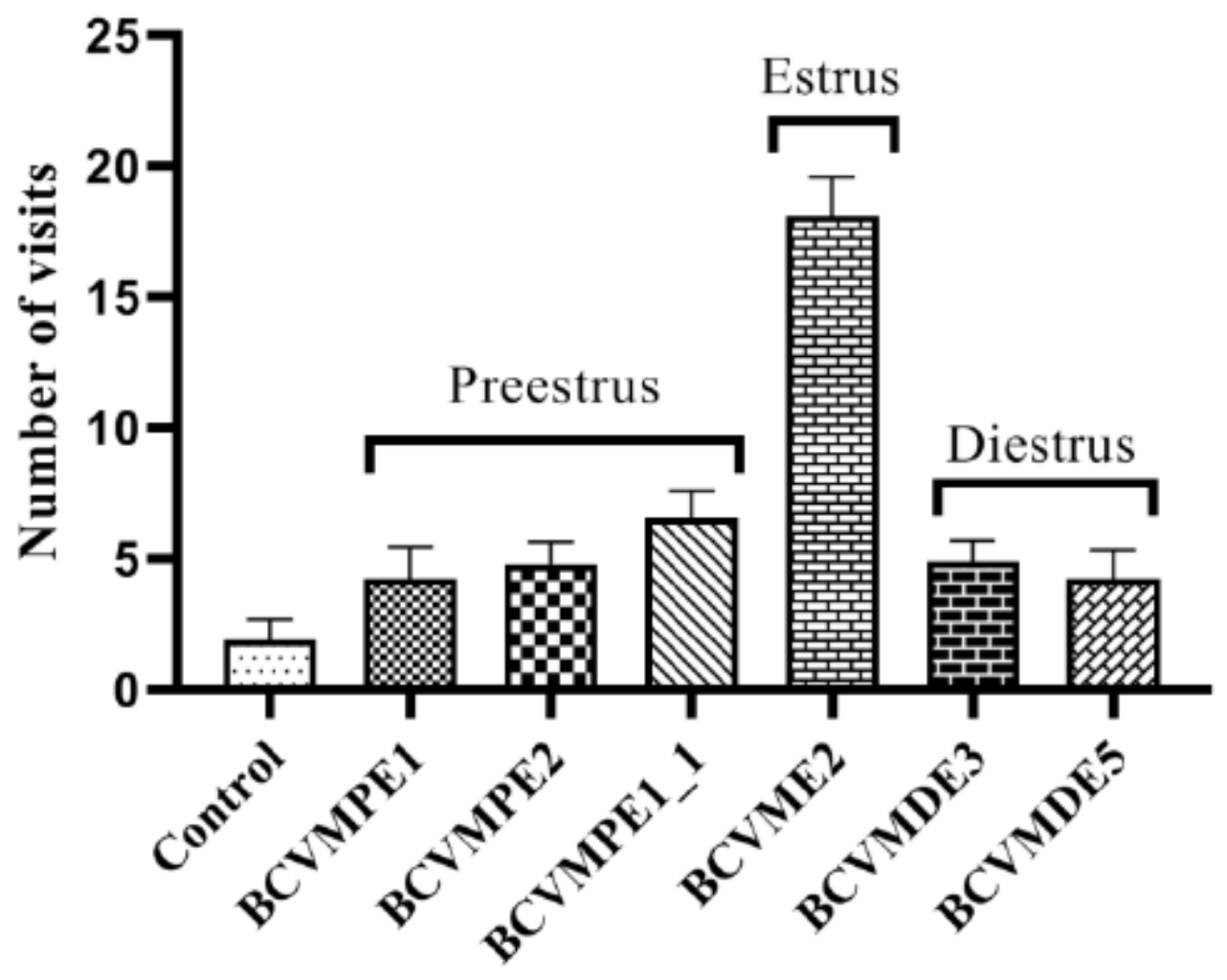

Figure 2

Ability of mice to differentiate the CVM bacteria by sniffing bacterial volatile samples. Bars show the number of visits by mice towards bacterial volatile from buffalo CVM. 


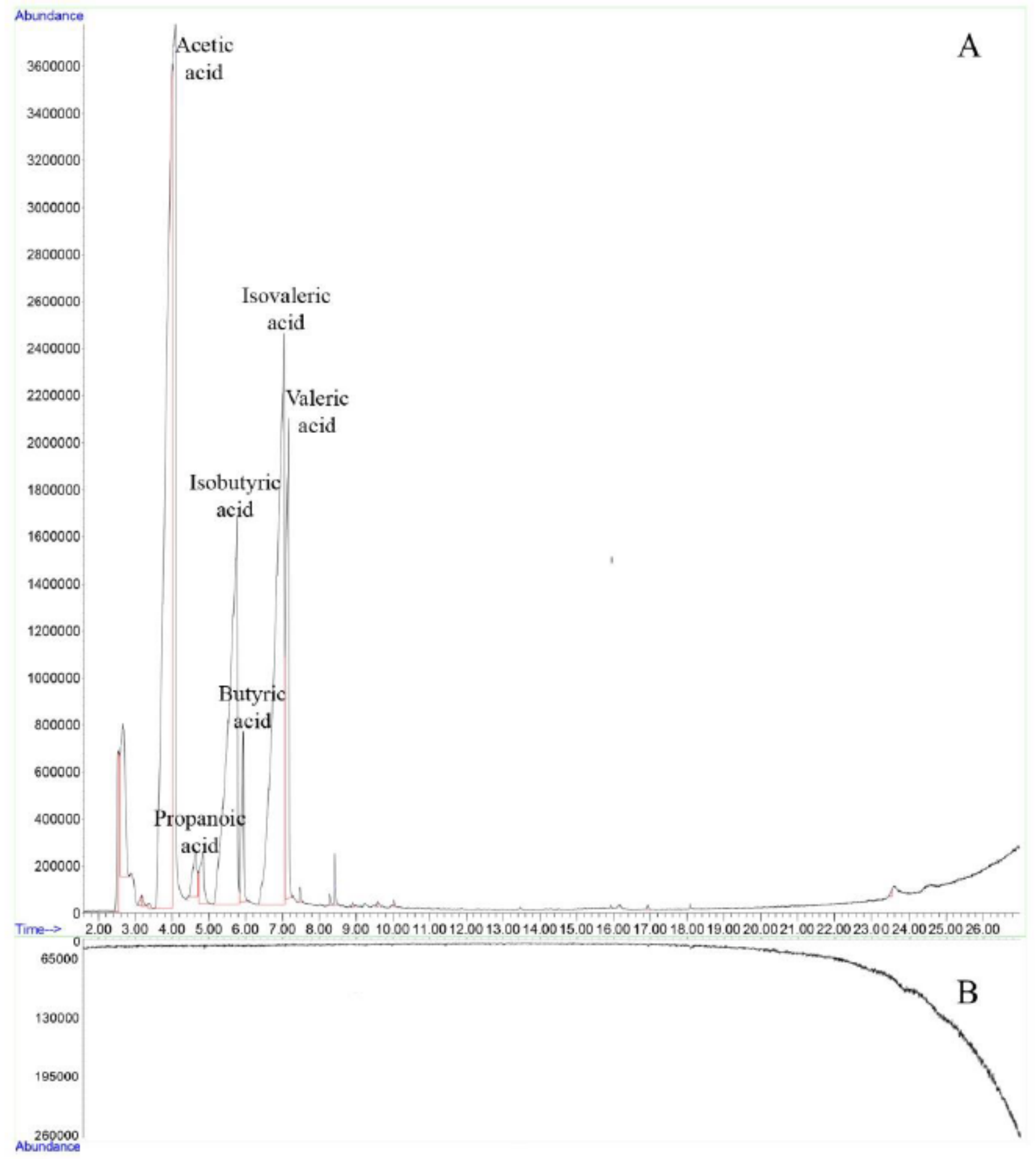

Figure 3

Chromatogram of bacterial secretory substance. A. S. pasteuri and B. LB broth. 


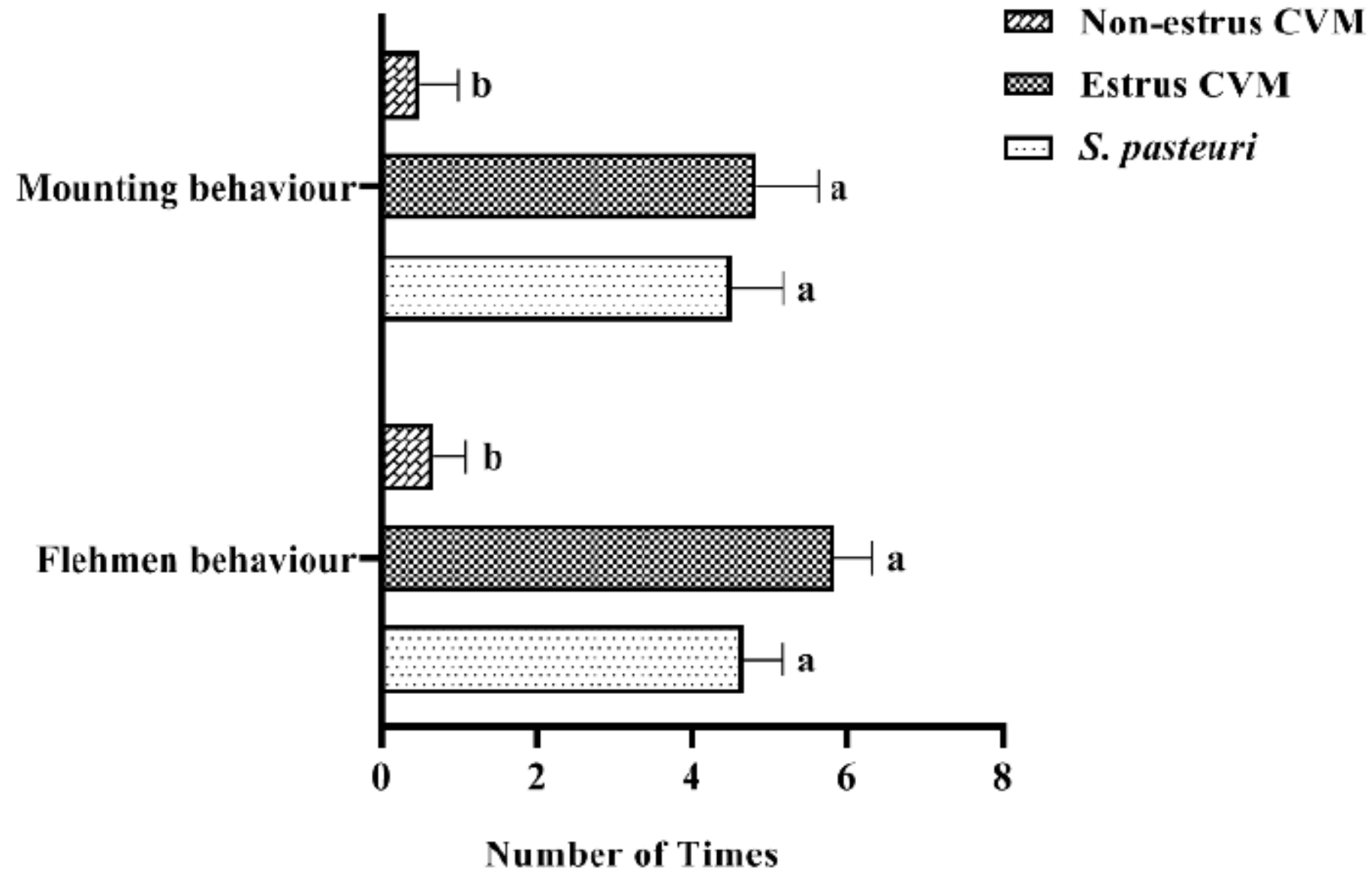

Figure 4

Behavioural assay. Bull behaviour towards the volatile sources. $n=6$; Values are represented as Mean $\pm S E M$. Bars having same letters indicate no significance.

\section{Supplementary Files}

This is a list of supplementary files associated with this preprint. Click to download.

- Supplementaryfiles2.1.docx 